\title{
A New Ultrasonic-based device for Accurate Measurement of Oil, Emulsion, and Water Levels in Oil Tanks
}

\author{
MAHMOUD MERIBOUT ${ }^{\mathbf{1}}$, MOHAMED HABLI ${ }^{\mathbf{1}}$, AHMED AL-NAAMANY $^{\mathbf{1}}$, \\ and KHAMIS AL-BUSAIDI ${ }^{2}$ \\ ${ }^{1}$ ECE Department, College of Engineering, SQU University, Oman. \\ ${ }^{2}$ PDO Corporation, Mucast, Oman.
}

\begin{abstract}
In the oil industry, many applications require the measurement of more than one liquid level interface, often in challenging environments. In this paper, an ultrasonic technique has been developed to examine the propagation of ultrasonic waves in the oil, water, and mixed oil-water liquids. The technique is expanded to determine the oil, emulsion, and water levels in an oil tank. A dedicated compact, low-cost, and programmable ultrasound-based Multi-layer level measurement (MLLM) device has been designed and implemented. The advantages of the new method over the current methods include contactless distance measurement, higher accuracy, lower cost, user friendly, simpler setup, and using non-nuclear rays. Additionally, the use of ultrasonic waves for the measurement has the advantage over light-based methods of being insensitive to dusty and smoky environment and almost independent of the object material and surface. Preliminary experiments have been conducted on the device. In this paper, the design and operating parameters of this device are discussed and evidence for the satisfactory performance is given.
\end{abstract}

Key-Words: - Ultrasonic Device, Emulsion Level Detection, Oil Tank, Multi-layer Level Measurement

\section{Introduction}

Oil producing institutions in many parts of the world are still faced with the problem of producing water and gas together with oil from their oil fields. Separating these three components from each other is a must. Such separation is usually done in stages. In one of these separation stages oil and water mixture is allowed to settle in large tanks for a short period of time. This process will cause the oil and water mixture to separate. However, the separation will consist of three components, oil at the top, oil/water mixture in the middle, and water at the bottom. Water will then be pumped out from the tank. However, in order not to pump out oil with water, the level of the mixed liquid (water-oil) need to be monitored continuously, especially during the pumping process. In [7] an extensive literature review on currently available level measurement methods, measuring devices and sensors has been investigated. The authors claimed that most of the devices have been designed to detect only the level of the top of the liquid in the tank. These measurement sensors include RF capacitance, conductance, nuclear, radar, differential pressure, optical switches, and ultrasonic. A microwavebased sensor is among the fewer devices which has been recently designed for extraction of the levels of the emulsion layers in the tank $[1,2,3]$. However the system is expensive. Additionally, the high energy of the microwaves makes the solution inappropriate for combustible liquids.

In this paper, a new ultrasonic-based hardware device for MLLM is presented. The hardware design of both the ultrasound devices and the tanks as well as the placement of the sensors in the tank will be described. The property of the Ultrasonic transducer such as frequency and amplitude will 
also be defined. These properties have been carefully selected through extensive laboratory experimental testing. The actual results are very encouraging and demonstrate that the device can easily measure, with a very good accuracy, the interface in a single vessel. Furthermore, since its electronics is placed outside the tank, the device can work in hazardous, clean, or sterile environments and cope with surface foam or bottom sludge. Hence the approach can be extended to allow the measurement of other fluid types as well.

\section{The Multi-level Detection Sensor Hardware Architecture}

\subsection{Concept}

The basic idea of our device is that the amount of ultrasound waves received and its speed depends upon the density of the liquid. In [6], it is shown that the acoustic impedance of the water and oil (1.4 and 1.07 respectively) are different. Therefore, different response (in terms of the magnitude of the received ultrasound pulse) of both liquids should be expected. Hence, by measuring the signal response at different vertical positions in the tank the two levels of the interface can be measured. Figure 1 shows the layout of the tank. An ultrasonic transmitter and receiver are mounted on two separate stands, at the same horizontal level of the tank. The signals from the receivers shall provide a complete profile for the contents of the tank. The advantage of this layout design is that the results are independent from the geometrical and chemical properties of the walls of the tank. The flowchart in Figure 2 shows the hardware architecture overview of the MLLM device. It's composed of an ultrasonic transmitterreceiver pair placed orthogonal to one another inside the two vertical stands and transmitting at a programmable frequency (e.g. 23, 40, and 150 $\mathrm{KHz}$ ).

\subsection{The Transmitter}

The actual transmitter circuit consists of an oscillator, an inverter, a bridge amplifier, and an ultrasound sensor. It was designed in such a way that it can transmit towards the ultrasound receiver a programmable gated pulses with a fixed frequency, $f_{0}$ (which can be equal to 23,40 , or 150 $\mathrm{KHz}$ respectively) which are pulse modulated with another carrier signal, $\mathrm{e}_{2}(\mathrm{t})$, of a period $T_{1}=$ $\frac{1}{f_{1}}=30 \mathrm{~ms}$ (Figure 3 ). This modulation technique was designed in order to correctly calculate the delay component of the received signal. The dedicated hardware solution is to use two oscillators which generate the signals $\mathrm{e}_{1}(\mathrm{t})=\mathrm{A}$ $\sin \left(2 \pi f_{0} t\right)$ and $e_{2}(t)=A \sin \left(2 \pi f_{1} t+\phi\right)$ respectively. The two signals are then fed to a microcontroller to generate a mixed signal, $\mathrm{e}_{3}(\mathrm{t})=$ $\mathrm{A}^{2}\left[\sin \left(2 \pi \mathrm{f}_{1} \mathrm{t}+\phi\right) * \sin \left(2 \pi \mathrm{f}_{0} \mathrm{t}\right)\right]$. This burst of ultrasonic pulses drives the piezoelectric transmitter TX that converts the electric signal, $\mathrm{e}_{3}(\mathrm{t})$, into acoustic waves, which should propagate through the vertical stand and the liquid before they reach the ultrasound receiver. Figure. 3 show the waveforms of the different signals generated by the ultrasonic transmitter.

\subsection{The Receiver}

The detected ultrasonic waveform is converted to a voltage by the piezoelectric receiver RX, and is fed into an analogue signal processing system, which consists of signal amplification using highspeed operational amplifier gain systems. The amplified signal is then fed to a second order antialiasing filter with $3 \mathrm{~dB}$ cut-off at $1.25 \mathrm{MHz}$ to create a pure signal of frequency $f_{0}$ (e.g. the same frequency used by the transmitter) The conditioned signal is converted to a digital waveform by a high speed, 12-bit analogue-todigital converter which samples at 2.5 Megasamples per second (MSPS), to discretisize and digitally quantify the waveform. The sampled data is stored in one Megabyte of onboard RAM for post-processing on a PC. The post-processing consists of determining the frequency components of the waveform using a Fast Fourier Transform (FFT) algorithm. The FFT components of the received signal are then analyzed for further processing. The analysis of the received signal in the frequency domain has the advantage to provide accurate results, regardless of the amount of noise surrounding the device. 
The other output of the amplifier is fed to a comparator (delay detector in Figure 2), which detects portions of the received signal having significant amplitude. This allows an immediate calculation of the delay between the transmitted and received pulses in the time domain.

\section{Driving Factors for the Design of the Tank}

\subsection{Distance between the two vertical stands}

In $[5,8]$, it has been shown that the ultrasound pulse reaches the receiver after a delay of:

$$
t_{\text {received }}=2 \frac{Z_{T}}{v_{T}}+\frac{Z_{F}}{v_{F}}
$$

Where $Z_{T}$ and $Z_{F}$ are the depths of the tubes and the distance separating the two vertical stands respectively, whereas $v_{T}$ and $v_{F}$ are the sound velocity in the vertical stand and the liquid respectively. In [1], it has been shown that the oil and water have a significant difference of velocity of the ultrasound waves. Hence, to have a significant difference of delay, the distance separating the two vertical stands should be high (e.g. at least more than $1 \mathrm{~cm}$ ). However, this may engender an additional damping of the ultrasonic waves. Therefore, the design of the tank was performed in such a way that the distance of the two stands can be easily modified (e.g. from $1 \mathrm{~cm}$ to $25 \mathrm{~cm}$ ). The optimal distance should then be deduced during the experiments.

\subsection{Material property of the vertical stands}

Another leading factor influencing the attenuation is the acoustic impedance or bulk modulus. At a boundary between two objects (e.g., liquid-vertical stand) with different ultrasonic impedances, there is a reflection. The reflection coefficient is directly related to the impedance difference between the two media [3].

$$
R=\frac{Z_{2}-Z_{1}}{Z_{1}+Z_{2}}
$$

This led us to use the glass since its property is simultaneously close to the water and oil.

\section{Preliminary Results}

To test the performance of our new device and to refine more the design of the tank, extensive experiments have been conducted in five consecutive steps. For most of these steps, the analysis of the results was performed in both time domain (delay and magnitude of the received and transmitted signals) and frequency domain (FFT characteristics).

\subsection{First Step of the Experiments: Driving Factors for Designing the Vertical Stands in the Tank}

At first, several tests were performed on two small containers of similar size $(2 \mathrm{~cm} \times 5 \mathrm{~cm} \times 10$ $\mathrm{cm}$ ), one containing the oil (engine oil) and the other one the water. The goal of these experiments was to know the nature of the received ultrasound waves when using these two fluids and the reliability of the analog sensors as well. These sensors were put at the same horizontal axis so that a maximal power can be received. Tables 1 and 2 shows the results obtained for the difference in phase between the ultrasonic waves of the transmitter and receiver $(\Delta \Phi)$ and the damping ratio, $\frac{A_{r}}{A_{t}}$ (where $A_{t}$ and $A_{r}$ are the amplitudes of the transmitted and received ultrasonic waves respectively) respectively.

All the experiments have been conducted on the oil and water using three different frequencies: 23 $\mathrm{KHz}, 40 \mathrm{KHz}$, and $150 \mathrm{KHz}$. Figure 4 shows the different parameters being measured.

From the tables, we can deduce that the speed of the ultrasound waves in the water is faster than in the oil. Also, the repeatability for both the delay and the damping is good. The best accuracy could be obtained with the frequency $f_{0}=40 \mathrm{KHz}$. With this frequency, the results of the delay (in $\mu \mathrm{s}$ ) were $4.3222 \pm 0.35$ and $5.07 \pm 0.25$ for the water and oil respectively. This is enough to distinguish between the oil and water. Our conclusion is then to focus on $40 \mathrm{KHz}$ sensors in the final set of experiments.

Following this first step of experiments, one major observation was that the transmitter and receiver 
sensors must touch the surface of the container. Otherwise, the transmitted signal will be strongly damped. This result is logic according to the equation (1) since the introduction of an additional layer (e.g. air) with different acoustic impedance will generate a stronger reflection of the ultrasound waves. This observation was taken into consideration for the design of the vertical stands: the pair of ultrasonic sensors shall touch the walls of the vertical stands. Figure 5 illustrates the design of the tank. Both the ultrasonic transmitter and receiver devices are placed in two separate stands in such a way that the distance separating the devices to the wall of the stand is equal to the height of the ultrasonic sensor. E.g. $d_{1}=10 \mathrm{~mm}$ (since the ultrasonic sensor is the highest sensor among all the electronic components of the board). In this way, the ultrasonic waves can propagate through only two mediums (e.g. fluid and glass material of the stand).

\subsection{Second Set of Experiments}

The second set of experiments was performed on the two containers, already described in section 3 . The two containers contain the oil and water respectively. In contrary to the experiments done during the first step, the transmitter for the actual experiment was designed in such a way that it sends a burst of ultrasonic waves as shown in Figure 6. Additionally, Figure 6 also shows the different parameters being measured. These parameters are the delay between the two trains of pulses $\left(t_{\mathrm{d}}\right)$ and the attenuation ratio between the received and transmitter signal $\left(\frac{A_{r}}{A_{t}}\right)$.

Figure 7 show the results of the received ultrasonic waves for the water and oil respectively. We could observe that the received signal was amplitude-modulated and that the two parameters $\Delta \Phi$ and $A_{\mathrm{r}} / A_{\mathrm{t}}$ are very sensitive to the position of the ultrasound sensors in the tank. However, for the two liquids, the repeatability of the measurements was $+-2 \%$ and $+-1.5 \%$ for the water and oil respectively. The damping of the signal was more significant for the ultrasound of 150 $\mathrm{KHz}$. This is normal according to the equation 1 since the level of the wave is inversely proportional to the square of the frequency.
This second set of experiments confirm the feasibility of the concept since the delays $\left(t_{\mathrm{d}}\right)$ and the attenuation ratio $\left(\frac{A_{r}}{A_{t}}\right)$ were significantly different in all cases and fit the theoretical study that the propagation of the ultrasound waves in the oil are faster in the water. Additionally, the analysis of the results in the frequency domain was done. Figure 8 shows the typical Fourier transform information, relating signal amplitude to the frequency spectrum of the signal for the water and oil respectively. Clearly, a strong fundamental component is present at $f_{0}(40 \mathrm{kHz})$. The harmonics obtained for the oil and water were slightly different. The power spectrum of the received signal may then be another additional parameter for detecting the emulsion layer between the oil and water.

In addition of the delay and amplitude ratio parameters already described in section 3, we also considered the first and second frequency harmonics of the received signal (F1 and F2) and the Root Medium Square (RMS), defined as:

$$
\operatorname{RMS}(v)=\sum_{i=1}^{T} \sqrt{v(i)^{2}-\overline{v^{2}}}
$$

Where $\bar{v}$ is the average of the signal $v$. The RMS parameter is an indication of the fluctuation of the amplitude of the signal, relative to its average in the time domain. A clear differences of all these parameters between the oil and water was observed.

\subsection{Third Step of Experiments: Preliminary results on the tank}

The last set of experiments was conducted on the designed tank. The tank was containing only water and the distance between the stands was set to $1.5 \mathrm{~cm}$.. The received amplitude modulated signal could be clearly identified, as well as the fundamentals and harmonics of its FFT. The next phase of experiments shall involve oil and deeper analysis of the received signals to detect the position of the emulsion layer in the tank 


\section{Conclusion and Recommendations}

In this report, the results obtained following an initial testing of new acquired ultrasound sensors were shown and the proposed MLLM device initial design was conducted. The results suggest that interface detection of oil and water using ultrasound is not only reasonable from a physics point of view, but also form an integrated electronics point of view. The advantages of our new proposed technique over the current available techniques can be summarized as follows:

1- High accuracy, safety, and can be used in multi-layers level detection (e.g. more than one emulsion layer can be measured).

2- No physical contact with the liquid because the transducers are mounted inside a stand.

3- No possibility of leakage or contamination.

4- Measurement is independent of pressure, liquid densities, and the presence of vapor and foam on the surface of the liquid.

5- Easily retrofits to existing vessels without welding.

The received ultrasound waves should be continuously digitalized by a low-cost, compact and real-time hardware system. This system transfers then the collected data to a Personnel Computer (Pentium IV-based Personnel Computer) in which Digital Signal Processing algorithm is performed.

A suitable calibration procedure was implemented. Therefore, the system represents an important tool in other related systems such as determining the composition fraction of oil and water in multiphase systems. Moreover, the method can be extended for level measurement of toxic, aggressive or corrosive liquids. This research platform is the first step in achieving a commercially viable liquid-liquid interface system.

The time domain analysis of the received ultrasonic waves provided very satisfactory results. During the next experiments, deeper analysis of the secondary harmonics will be conducted and reported.

\section{Acknowledgement}

The authors wish to thank Petroleum Development Oman (PDO) Corporation for supporting the actual work.

\section{REFERENCES}

[1], Able Instruments \& Controls Ltd, Sensors for level measurements, available from URL: http://www.able.co.uk/level.htm,2003.

[2] G. Betta , L. Ippoto and A. Scaflione, An optical fiber based technique for continuous level sensing, IEEE. Transactions Measurement, Vol. 44, pp. 686-689, June 1995

[3] Betta et al, Microcontroller-based performance enhancement of an optical fiber level transducer, IEEE Transactions on Instrumentation and Measurements, Vol. 45, No 2, April 1998.

[4] J.S. Charlton, Synetix-Dialog Alliance, and R.P. Lees, The Future of Three Phase Separator Control, SPE 77891 (2002).

[5] Foxoboro Inc, Intelligent $\mathrm{d} / \mathrm{p}$ transmitter for liquid level, interface, and density- flange mounted, available from URL: http://www.foxboro-

eckardt.com/pdf/144FP_2MI_A_001_en.pdf.

[6] Gemssensors Inc, What is reed Switch, available from URL: http://www.gemssensors.co.uk/level/p3-4-26.pdf.

[7] M Habli, A. Alnaamany, M. Meribout and K. Al-Busaidi, Development of an Oil/Water Level Measurement Device, Internal Report, May 2003.

[Tracerco 02] Tracerco Inc., Radiation level Measurement, available from URL: http://www.tracerco .com. 


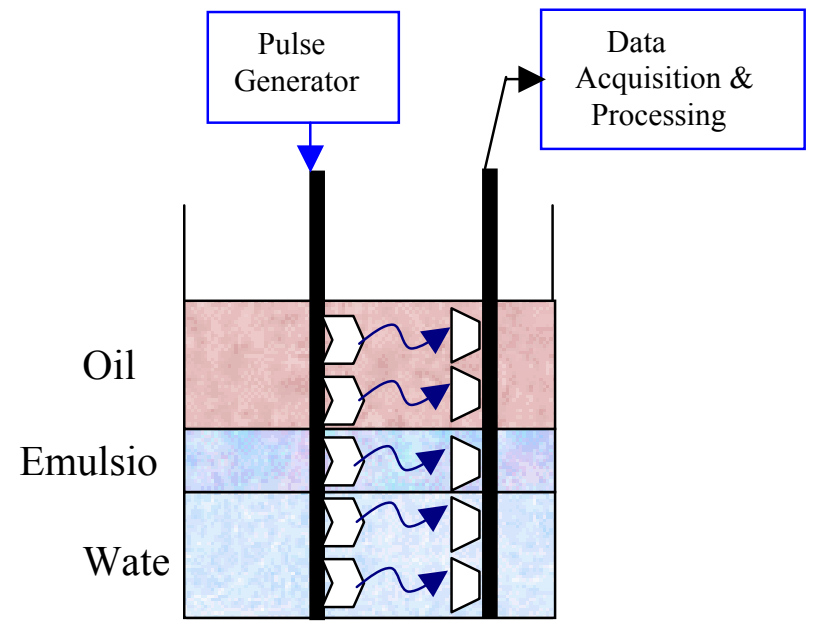

Figure 1 Multi-layer Level Measurement: Concept.

(a) Transmitter

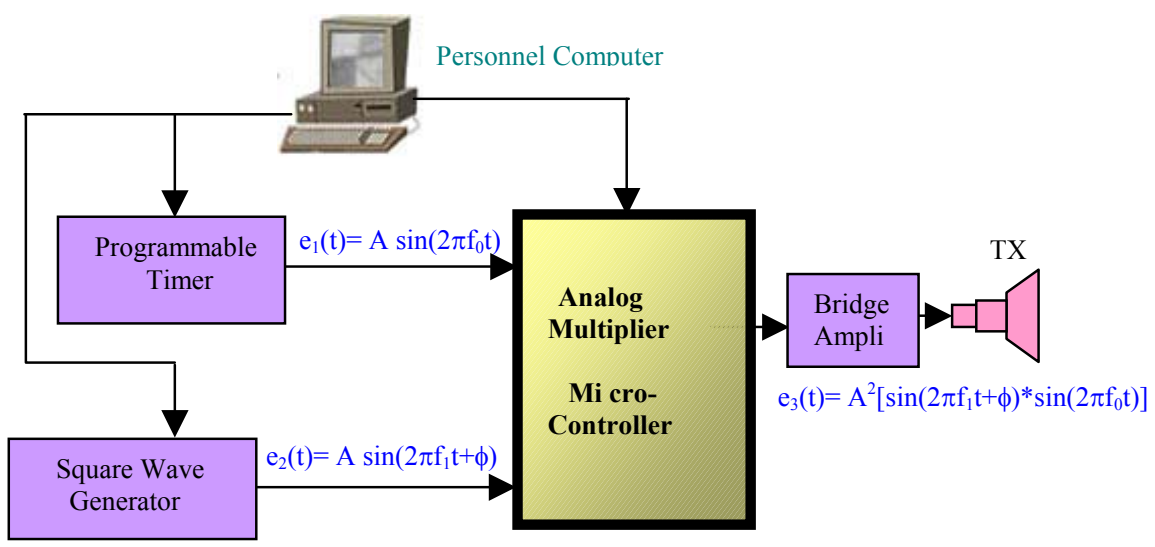

(b) Receiver.

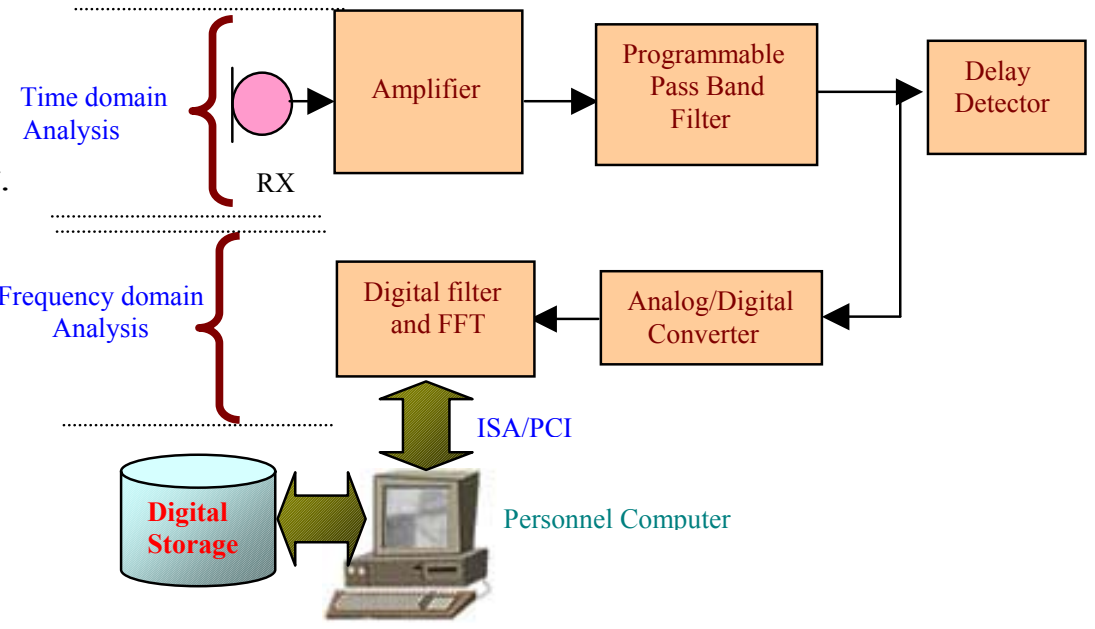

Figure 2 Hardware Block diagram of Detection System. 




Figure 3 Pair of Electrical Signals Generated in the Transmitter (a) and (b) and the Resulting Output (c).

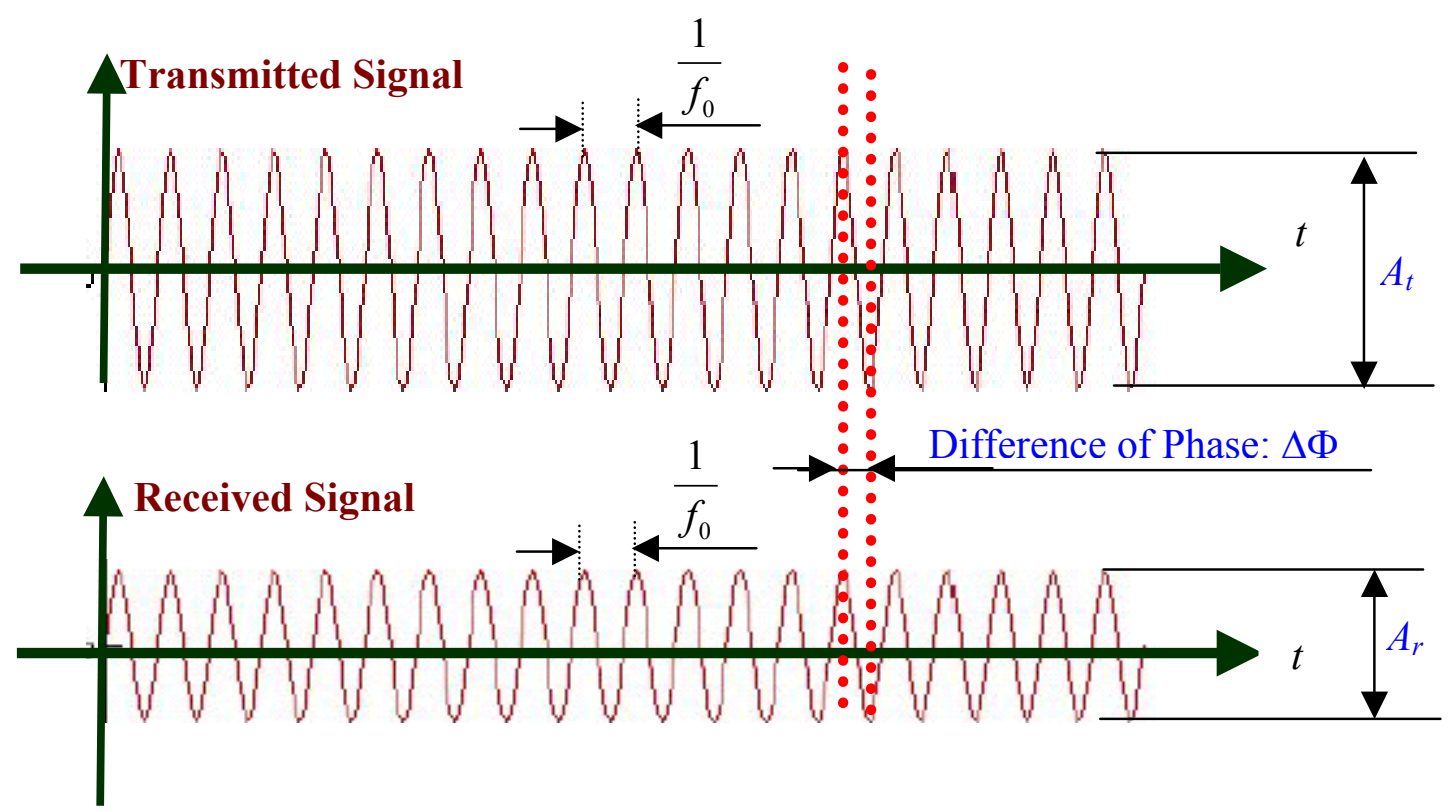

Figure 4 The two Parameters $\Delta \Phi$ and Ar Being Measured During the First Set of Experiment. 
Table 1 Difference in Phase of the Ultrasonic Waves in Oil and Water (in $\mu$ s)

\begin{tabular}{|c|c|c|c|c|c|}
\hline Ultrasounds & $\begin{array}{l}\text { Experiment } 1 \\
\text { Oil } \vdots \text { Water }\end{array}$ & $\begin{array}{c}\text { Experiment } 2 \\
\text { Oil: Water }\end{array}$ & $\begin{array}{c}\text { Experiment } 3 \\
\text { Oil } \vdots \text { Water }\end{array}$ & $\begin{array}{l}\text { Experiment } 4 \\
\text { Oil } \vdots \text { Water }\end{array}$ & $\begin{array}{c}\text { Experiment } 5 \\
\text { Oil }: \text { Water }\end{array}$ \\
\hline $24 \mathrm{KHz}$ & $37.6:$ & $36.8:$ & $36.4: 12.1$ & $36.4:$ & $36.6: 12.0$ \\
\hline $23 \mathrm{KHz}$ & $15.1:$ & 13.1 : & $14.8 ：$ & 14.0 : & $15.2 \vdots$ \\
\hline $40 \mathrm{KHz}$ & $4.8:$ & $5.0:$ & $5.2:$ & $5.3:$ & $5.1: 4.7$ \\
\hline $150 \mathrm{KHz}^{1}$ & - & - & - & - & - \\
\hline
\end{tabular}

${ }^{1}$ : For the $150 \mathrm{KHz}$ ultrasonic sensor, no received signal was observed. This can be explained by the fact the attenuation of the ultrasound waves is proportional to the square of the frequency. However, we should expect a better results if the walls of the container

Table 2 Damping ratio Factor $\left(\mathrm{A}_{\mathrm{r}} / \mathrm{A}_{\mathrm{t}}\right)$ of the Ultrasonic Waves in Oil and Water.

\begin{tabular}{|c|c|c|c|c|c|}
\hline Ultrasounds & $\begin{array}{c}\text { Experiment } 1 \\
\text { Oil } \vdots \text { Water }\end{array}$ & $\begin{array}{l}\text { Experiment } 2 \\
\text { Oil: Water }\end{array}$ & $\begin{array}{c}\text { Experiment } 3 \\
\text { Oil } \vdots \text { Water }\end{array}$ & $\begin{array}{l}\text { Experiment } 4 \\
\text { Oil } \vdots \text { Water }\end{array}$ & $\begin{array}{c}\text { Experiment } 5 \\
\text { Oil }: \text { Water }\end{array}$ \\
\hline $24 \mathrm{KHz}$ & $0.6: 0.4$ & 0.3 & 0.3 & $0.6:$ & $0.6: 0.3$ \\
\hline $23 \mathrm{KHz}$ & 0.2 & 0.2 & 0.3 & $0.4:$ & $0.2:$ \\
\hline $40 \mathrm{KHz}$ & 0.05 & 0.07 & $: 0.08$ & $0.1: 0.08$ & $0.1: 0.07$ \\
\hline $150 \mathrm{KHz}^{1}$ & - & - & - & - & - \\
\hline
\end{tabular}

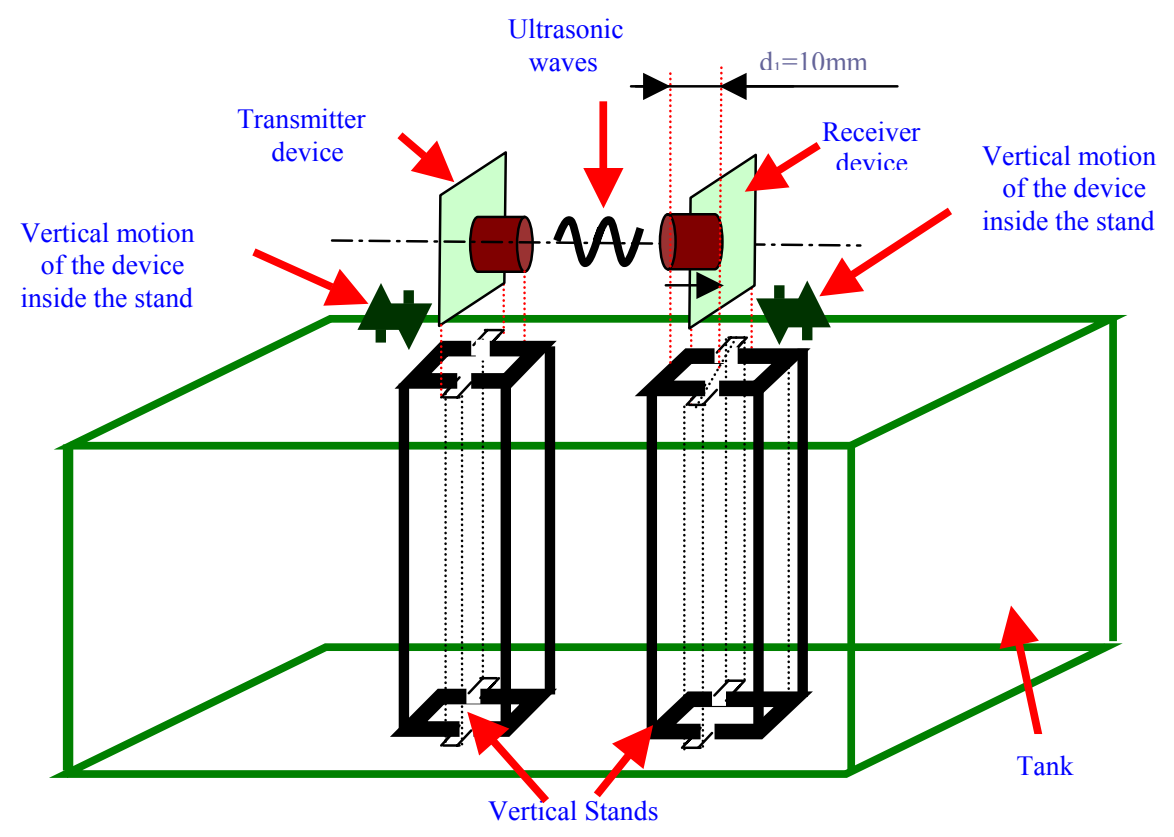

Figure 5 Design of the Tank and the Vertical Stands for Emulsion Layer Detection. 


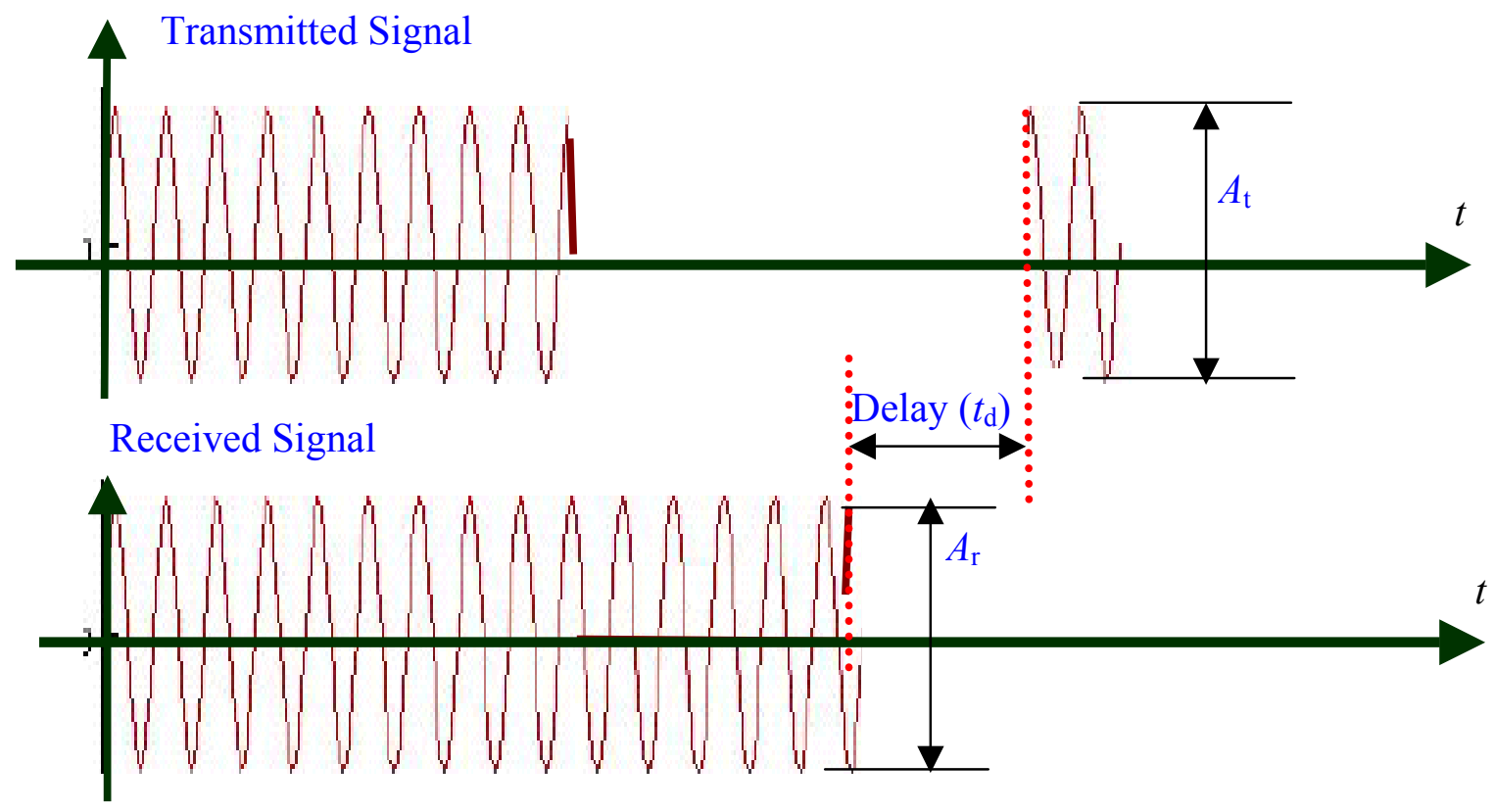

Figure 6 The two Parameters $\Delta \Phi$ and $A_{\mathrm{r}} / A_{\mathrm{t}}$ as Being Measured During the Second Set of Experiments.

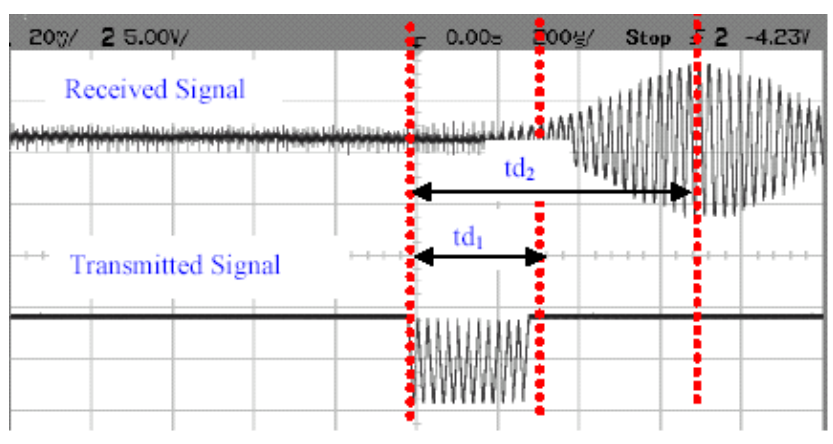

(a)

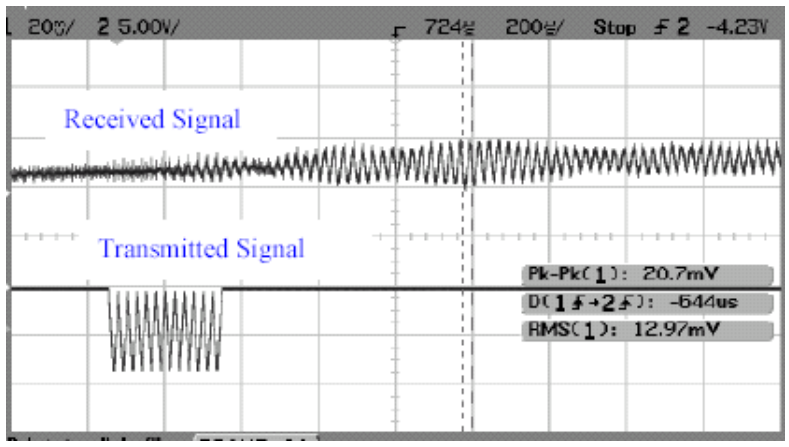

(b)

Figure 7 Transmitted and Received Signals with the Water (a) and oil ()b Containers (time domain).

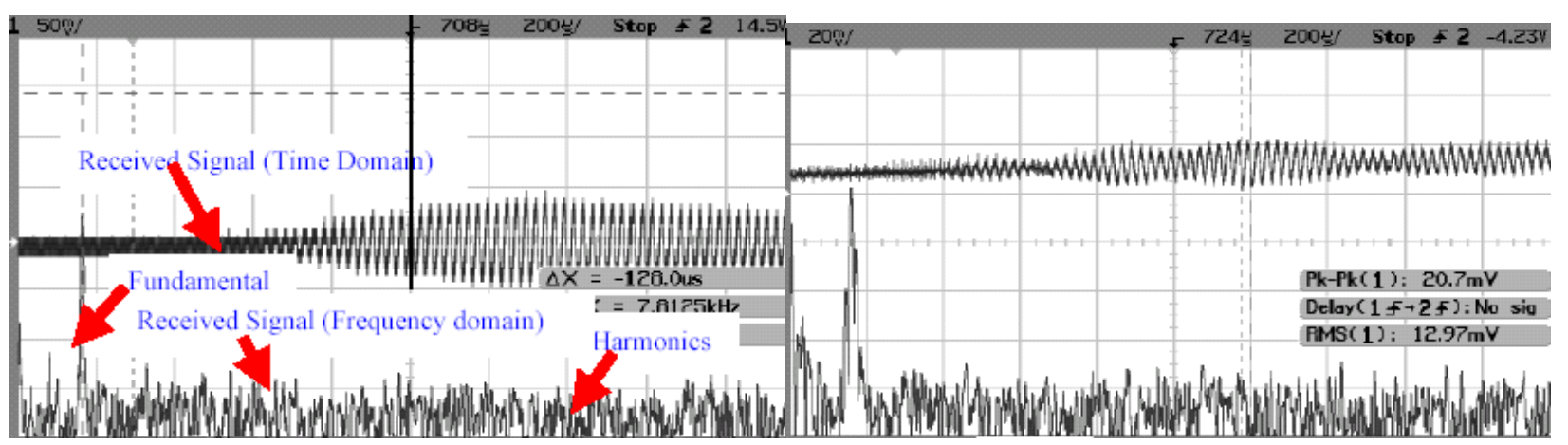

(a)

(b)

Figure 8 Transmitted and Received Signals with the Water (a) and oil ()b Containers (frequency domain). 